\title{
Biotecnología aplicada al desarrollo agropecuario colombiano
}

\section{Biotechnology applied to colombian agricultural development}

\author{
Biotecnologia aplicada ao desenvolvimento \\ agricola colombiano
}

\begin{abstract}
Sandra Patrícia Montenegro Gómez¹ \& Yeni Katerine Hernández Ossa²
Licenciada en Biología y Química, Especialista en manejo y conservación de suelos y aguas, Magister en ciencias agrarias, énfasis suelos, Doctora en Ciencias área de concentración microbiología Agrícola. ${ }^{2}$ Ingeniera Agrónoma, Especialista en Biotecnología Agraria.

${ }^{1,2}$ Centro de Investigación de Agricultura y Biotecnología -CIAB. Dosquebradas, Risaralda. Colombia.
\end{abstract}

1sandra.montenegro@unad.edu.co, 2ykhernandezo@unadvirtual.edu.co

\section{Resumen}

Colombia tiene como objetivo para 2025, ubicarse entre los tres líderes del sector biotecnológico en América Latina, para lo cual requiere conectarse con las tendencias mundiales enmarcadas en el desarrollo de actividades de bioprospección que actúen en armonía con el entorno ambiental garantizando la seguridad alimentara. Por lo tanto las tendencias de consumo global en el mercado agrícola presentan nuevas oportunidades de negocios alrededor de bioinsumos, aditivos funcionales para alimentación animal, agricultura sostenible, bioremediación de suelos y aguas, reproducción in vitro, semillas mejoradas con biotecnologías de punta; direccionadas a mejorar la calidad, el rendimiento y reducir al mínimo el uso de prácticas agrícolas tradicionales que consumen energía y contaminan el medio ambiente. Colombia actualmente cuenta con varios centros de investigación y universidades con dotación y capacidades para adelantar investigaciones en tecnologías de avanzada, pese a que existen estudios importantes en el campo agrícola y pecuario, el alcance de la bioprospección en el país es bajo, en comparación a otros países latinoamericanos, como Brasil con más de 800 centros de bioprospección, Costa Rica con 43, Colombia se encuentra en gran desventaja con alrededor de 20 centros, por lo tanto el esfuerzo para ubicarse a la vanguardia en investigación biotecnologica es muy grande y se requiere del fortalecimiento en investigación básica y aplicada, apoyada en implementación de políticas institucionales de regulación y agilización de procesos biotecnológicos que desarrollen productos innovadores para que diferentes biotecnologías tengan éxito comercial, de acuerdo a los objetivos propuestos por el gobierno nacional.

Palabras clave: biotecnología, bioprospección, desarrollo agropecuario, sustentabilidad

\section{Abstract}

Colombia aims to rank among the three leaders in the biotechnology sector in Latin America for 2025, which requires to connecting with global trends framed in the development of bioprospecting activities, in harmony with the environment and ensuring food safety. Therefore global consumer trends in 
the agricultural market present new business opportunities regarding bioinputs, functional additives for animal feeding, sustainable agriculture, bioremediation of soil and water, in vitro reproduction, and improved seeds with high end biotechnologies; with the goal of improving the quality, performance and minimize the use of traditional agricultural practices which consume energy and pollute the environment. Colombia currently has several research centers and universities with resources and capabilities to conduct research regarding high end technologies and, even though there are significant research in the agricultural and livestock field, the scope of bioprospecting in the country is low compared with other Latin American countries, such as Brazil with more than 800 bioprospecting centers, Costa Rica with 43 , Colombia is seriously disadvantaged with just about 20 centers, therefore a great effort to be at the forefront in biotechnology research is required; and the strengthening of basic and applied research is necessary based on implementation of regulation and speeding-up institutional policies of biotechnology processes that develop innovative products so biotechnologies have commercial success, according to the goals set by the national government.

Key-words: biotechnology, bioprospecting, agricultural development, sustainability

\section{Resumo}

A Colômbia tem como objetivo para 2025 se posicionar entre os três líderes do setor biotecnológico em America Latina, para o qual é preciso fazer contato com as tendências mundiais enmarcadas no desenvolvimento de atividades de bioprospeção que trabalhem em armonia com o entorno ambiental garantindo a segurança alimentar. Portanto, as tendências de consumo global no mercado agrícola presentam novas oportunidades de negócios em torno a bioinsumos, aditivos funcionais para alimentação animal, agricultura sostenível, biorremediação de solos e águas, reprodução in vitro, sementes melhoradas com biotecnologias apropriadas que apontam a melhorar a qualidade, a produtividade e reduzir ao mínimo o uso de práticas agrícolas tradicionais que consumem energía e poluem o meio ambiente. A Colômbia atualmente conta com vários centros de pesquisa e universidades dotadas e com capacidade para conduzir pesquisas em tecnologías avanzadas; embora existam estudos importantes na área agrícola e pecuária, o alcance da bioprospeção no país é baixo quando comparado com otros países latinoamericanos como Brasil, o qual dispõe de mais de 800 centros de biopropeção, Costa Rica com 43, sendo que Colômbia apresenta desvantagem ao contar com em torno de 20 centros. Portanto, o esforço para se posicionar na vanguarda em investigação biotecnológica é muito grande e precisa do fortalecimento em pesquisa básica e aplicada, soportada na implementação de políticas institucionais de regulação e agilização de procesos biotecnológicos que desenvolvam produtos innovadores para que diferentes biotecnologias tenham êxito comercial conforme os objetivos propostos pelo governo nacional..

Palavras-chave: biotecnologia, bioprospecção, desenvolvimento agrícola, sustentabilidade

\section{Introducción}

Las primeras aplicaciones de biotecnología agrícola se sustentan en cría selectiva mediante el uso de ingeniería genética para producir rápidamente animales y plantas con rasgos deseables. Los nuevos rasgos de la biotecnología agrícola tienen por objeto mejorar la calidad y el rendimiento y reducir al mínimo el uso de prácticas agrícolas tradicionales que consumen energía y contaminan el medio ambiente (Shmaefsky, 2013). Dentro de la clasificación de la biotecnología a través de colores, el color verde concentra estudios en agricultura, biotecnología ambiental, biocombustibles, 
biofertilizantes, biorremediación y geomicrobiología (DaSilva, 2004). De acuerdo a lo planteado en la Agenda de Conocimiento - Universidad Nacional de Colombia (Chaparro et al., 2012) en concordancia con el Ministerio de Investigación, Ciencia y Tecnología de Nueva Zelanda, MoRST (MoRST, 2005), las tendencias mundiales hacia 2020 en biotecnología verde, se fundamentan en productos mejor balanceados. En lo que respecta a la parte pecuaria, suministrar a los animales alimentos con más concentración de aminoácidos y nutrientes que podrían proporcionar ventajas ambientales. En relación al campo vegetal, cultivos con mejores atributos nutricionales y resistentes a diversos estres ambientales; asociados a los cultivos, están los productos microbiológicos como biofertilizantes y bioplaguicidas.

Hasta ahora la mayor parte de la investigación básica en biotecnología agrícola y sus avances se ha fortalecido en países desarrollados; en contraste los países en desarrollo con la mayor variedad de la biodiversidad en el mundo, poco han trabajado en la caracterización de especies de plantas y animales para evaluar su potencial de producción y su capacidad para resistir a enfermedades y tensiones ambientales o para garantizar su conservación a largo plazo (FAO, 2004) Colombia busca reconocimiento como líder en el desarrollo, producción, comercialización y exportación de productos de alto valor agregado derivados del uso sostenible de la biodiversidad (Narváez, 2015), siendo el objetivo para 2025, posicionarse como uno de los tres líderes del sector biotecnológico en América Latina. En la Tabla 1 se presentan algunas biotecnologías relacionadas con el sector agropecuario con alta probabilidad de alcanzar el mercado en 2030. Las riquezas naturales colombianas, acentúan la importancia del desarrollo en biotecnología para sectores como el agropecuario (Buitrago, 2012), sin embargo, una de las cuestiones que se requiere afrontar en primer término es la baja capacidad para el desarrollo de actividades de bioprospección. Existen aproximadamente 20 centros de bioprospección moderna en Colombia, mientras que Brasil cuenta con más de 800 y Costa Rica con 43. Es patente que el desarrollo de este tipo de centros en Colombia está por debajo de sus capacidades. Por lo tanto se hace necesario la implementación de políticas institucionales de regulación y agilización de procesos biotecnológicos que desarrollen productos innovadores, estas son las claves para que diferentes biotecnologías tengan éxito comercial para el 2030 de acuerdo a la OECD (2009).

Tabla 1. Algunas biotecnologías relacionadas con el sector agropecuario con alta probabilidad de alcanzar el mercado en 2030.

\begin{tabular}{|c|c|c|}
\hline Producción primaria & Salud & Industria \\
\hline $\begin{array}{l}\text { Uso generalizado de selección asisti- } \\
\text { da por marcadores o genómica (MAS) } \\
\text { en mejoramiento de plantas, ganado, } \\
\text { peces y mariscos. }\end{array}$ & $\begin{array}{l}\text { Muchos productos farmacéuticos nue- } \\
\text { vos y vacunas, basadas en conocimien- } \\
\text { tos biotecnológicos, reciben aprobación } \\
\text { de comercialización cada año. }\end{array}$ & $\begin{array}{l}\text { Enzimas mejoradas para una amplia } \\
\text { gama de aplicaciones en la industria } \\
\text { química. }\end{array}$ \\
\hline $\begin{array}{l}\text { Variedades modificadas genéticamen- } \\
\text { te }(\mathrm{GMO}) \text { de los principales cultivos y } \\
\text { arboles con mejor almidón, aceite y } \\
\text { contenido de lignina para mejora de } \\
\text { procedimiento industrial y producción. }\end{array}$ & $\begin{array}{l}\text { Nuevos productos nutracéuticos, } \\
\text { algunos de los cuales serán produ- } \\
\text { cidos por microorganismos modi- } \\
\text { ficados genéticamente y otros de } \\
\text { plantas o extractos marinos }\end{array}$ & $\begin{array}{l}\text { Mejora de los microorganismos que } \\
\text { pueden producir un número mayor } \\
\text { de productos químicos en un solo } \\
\text { paso, algunos de los cuales se ba- } \\
\text { san los genes identificados a través } \\
\text { de la bioprospección }\end{array}$ \\
\hline $\begin{array}{l}\text { Variedades mejoradas de los princi- } \\
\text { pales cultivos alimenticios y forrajeros } \\
\text { con mayor rendimiento, resistencia a } \\
\text { las plagas y tolerancia al estrés gene- } \\
\text { rados mediantes GMO. MAS intrage- } \\
\text { nésis o cisgenésis }\end{array}$ & $\begin{array}{l}\text { Seguridad alimentaria por el incre- } \\
\text { mento de producción y calidad de } \\
\text { las cosechas. }\end{array}$ & $\begin{array}{l}\text { Biocombustibles de alta densidad } \\
\text { de energía producidos a partir de la } \\
\text { caña de azúcar y fuentes de bioma- } \\
\text { sa ricas en celulosa }\end{array}$ \\
\hline $\begin{array}{l}\text { Clonación de animales de alto valor } \\
\text { genético y mejoramiento. }\end{array}$ & $\begin{array}{l}\text { Productos de origen animal con alta } \\
\text { calidad nutricional y funcional. }\end{array}$ & $\begin{array}{l}\text { Producción de alimentos con materias } \\
\text { primas de alta calidad nutricional. }\end{array}$ \\
\hline
\end{tabular}

Fuente: Cotes et al. (2012) 
Colombia cuenta con 153 firmas de base biotecnológica distribuidas en distintos sectores: en el sector agrícola 59 (38\%), sector alimentos y bebidas alcohólicas 50 (33\%), biocombustibles 12 (8\%), sector farmacéutico $8(5 \%)$, Universidades y Centros de Investigación 24 (16\%), (Buitrago, 2012), (Figura 1). De acuerdo a lo reportado por
Gonzales, Villa Latorre \& Bravo (2010) y Angarita (s. f.), el $54 \%$, de los grupos y centros de investigación colombianos enfocados en biotecnología trabajan en el ámbito agropecuario, indicando que la industria agropecuaria colombiana representa una gran oportunidad para que el país dé un importante salto económico y social (Narváez, 2015).

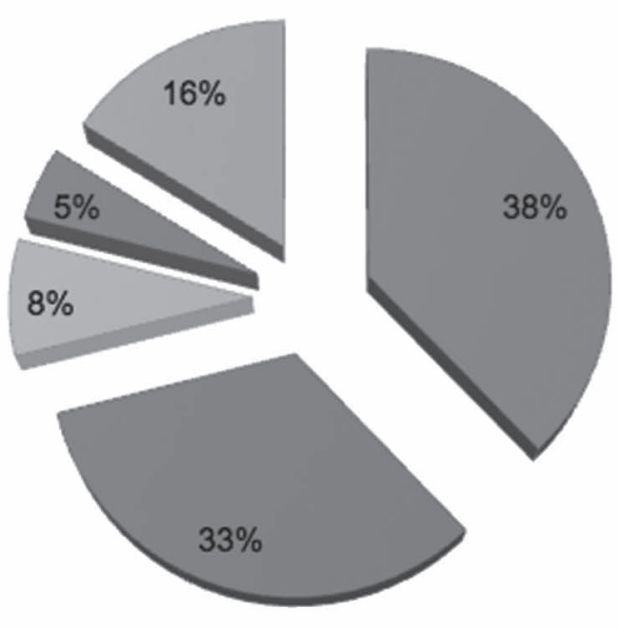

ISECTOR AGRICOLA

-SECTOR ALIMENTOS Y

BEBIDAS ALCOHOLICAS

घBIOCOMBUSTIBLES

$\square$ SECTOR

FARMACEUTICO

-UNIVERSIDADES Y

CENTROS DE

INVESTIGACION

Figura 1. Distribución del peso sectorial de la biotecnología en Colombia según el número de empresas.

Fuente: Narváez, (2015) con datos del informe INNpulsa-SILO

\section{Beneficios de la biotecnología para el agro colombiano}

Colombia es un país mega-diverso, pero es muy poco lo que se ha utilizado de esta riqueza para el desarrollo del sector agropecuario y la generación de bienes y servicios biotecnológicos, Narváez (2015), no obstante ha venido avanzando paulatinamente tanto en el campo agrícola como pecuario.

\section{Sector agrícola}

Entre las grandes tendencias de consumo en el mundo, el mercado agrícola presenta nuevas oportunidades de negocios alrededor de bioinsumos, aditivos funcionales para alimentación animal, agricultura sostenible, bioremediación de suelos y aguas, reproducción in vitro, semillas mejoradas con biotecnologías de punta (transgénicos o selección asistida por genómica). Colombia ha progresado paulatinamente en el establecimiento de colecciones de recursos biológicos de manera ex situ e in situ, a través de la promoción y apoyo de bancos de germoplasma que conservan recursos genéticos (Cotes et al., 2012). En el año 2002, Colombia ingresó a la lista de los países que utilizan los cultivos Genéticamente Modificados (GM), con la siembra del clavel azul. En el año 2003 fue aprobado el algodón GM y, en el 2007, el maíz GM fue sembrado por primera vez en el país bajo el esquema de siembras controladas. A finales del año 2009, Colombia aprobó la siembra comercial de rosas azules. Entre los cultivos mencionados el maíz representa la mayor distribución en el territorio colombiano (Figura 2). Actualmente el Centro de Agricultura Tropical CIAT, adelanta proyectos de investigación con GM en yuca, arroz y pastos; el Centro de Investigaciones Biológicas CIB, junto con la Universidad Nacional de Colombia Sede Medellín trabajan investigación en papa, el 
Centro Nacional de Cafeteros CENICAFE y el Centro Nacional de Investigación en caña de azúcar CENICAÑA trabajan investigaciones en café y caña respectivamente (Agrobio, 2014).

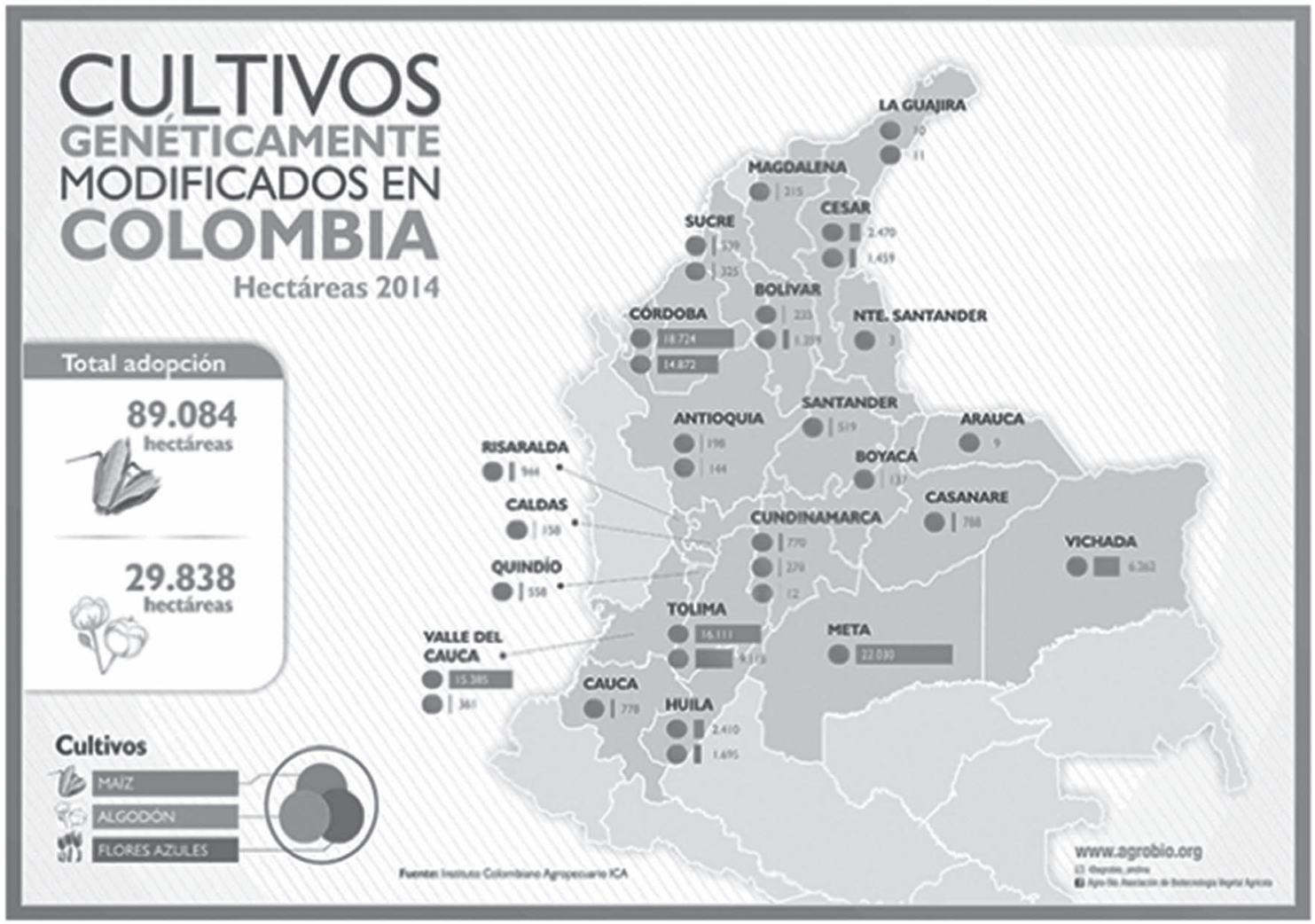

Figura 2. Distribución regional de cultivos genéticamente modificados en Colombia en el año 2014. Fuente: Agrobio (2014).

\section{Algunas investigaciones destacadas} en cultivos agrícolas y especies forestales

Arroz (Oryza sativa): El centro internacional de agricultura tropical (CIAT) ha venido adelantando variados estudios de transformación genética en diferentes especies de importancia económica en Colombia. El cultivo del arroz es afectado por diferentes enfermedades, plagas y factores climáticos, uno de las afectaciones principales es el virus de la hoja blanca trasmitido por un insecto vector Tagosodes orizicolus, la investigación realizada por Fory et al. (2002) se basó en adicionar una nueva fuente de resistencia en algunas variedades, se tomaron callos de panículas inmaduras de variedad indica Cica 8 a la cual se le insertó el gen de la N-proteína de RHBV por medio de plásmido pVR3 con la técnica bombardeo de partículas de oro recubiertas de ADN, el ensayo se realizó en invernaderos donde se usaron insectos virulentos.
La evaluación se basó en el nivel de resistencia, área foliar afectada, vigor de la planta y severidad de los síntomas; se observó una resistencia estable conferida por $\mathrm{N}$-proteína y la protección en edad temprana, "Se observaron muchas reacciones de resistencia incluyendo la producción de lesiones localizadas conocidas como una reacción de resistencia hipersensitiva. Los resultados a nivel de campo indican que la resistencia transgénica al RHBV puede ser utilizada para complementar las fuentes naturales de resistencia al virus" (Fory et al., 2002).

Caña de azúcar (Saccharum officinarum): E centro de investigación de la caña de azúcar (CENICAÑA) ha adelantado estudios en la creación de una caña genéticamente modificada, que tenga tolerancia al virus de la hoja amarilla. La investigación para una variedad GM CC84-75 se 
comenzó hace un poco más de 10 años, se realizó el procedimiento en laboratorio y en invernadero para tener un mejor control de bioseguridad; las plantas se llevaron a campo donde se realizó su seguimiento, este proceso fue la primera parte de la investigación se lograron obtener 46 plantas en el invernadero pero sólo 11 plantas pasaron a campo midiéndolas en dos ciclos de cultivo mostrando una diferencia poco significativa debido a que. "la población del virus en el momento cancerosas no causó el daño económico que se esperaba, y el lugar donde se realizaron las pruebas no era foco del virus" (AGROBIO, 2006). La segunda parte de la investigación se comenzó aproximadamente dos años después, se buscó validar la información y observar cuan estables son los transgenes para posteriormente dar a conocer a los demás países productores las posibilidades de la caña GM con la variedad CC85-92, y conferir resistencia a bacterias presentes en el cultivo, ninguna de estas cañas se comercializa actualmente.

Papa (Solanum tuberosum): Colombia es uno de los principales países que cultiva la papa amarilla y las plagas o enfermedades afectan la producción de este cultivo ocasionando grandes pérdidas para los agricultores. La Universidad Nacional de Colombia, junto a la Universidad McGill desarrollaron un estudio para el desarrollo de nuevas variedades de papa amarilla con mejor rendimiento, cualidades agronómicas, cualidades nutricionales, contenidos de compuestos benéficos para la salud y resistencia a gota. Además, se identificaron varios genes en papa involucrados en la resistencia a gota y compuestos con capacidad importante para disminuir el crecimiento de células cancerosas. Estos son los primeros cultivares de papa que propenden por la calidad nutricional en Colombia con mayor contenido de proteína y de minerales como hierro y zinc (Narváez et al., 2014).

La Corporación para Investigaciones Biológicas ubicada en Medellín viene realizando estudios para crear una línea de papa transgénica resistente a la polilla guatemalteca, que es una de las plagas de mayor importancia económica en Colombia, las investigaciones para la obtención de estas líneas llevan 12 años. En este caso se tomó la bacteria Bacillus thuringiensis para transformar las plantas genéticamente, se comenzó con siete materiales comerciales de los cuales sólo dos han mostrado potencial de resistencia a la polilla, estas son las variedades parda pastusa y Diacol Capiro R12; "esto significa que esas plantas han superado todas las pruebas moleculares, biológicas, químicas, inmunológicas realizadas hasta al momento y han demostrado hasta un $100 \%$ de resistencia a la plaga, pues han sido expuestas a un nivel alto de incidencia de plaga y logran resistir completamente" (AGROBIO, 2011). Estas líneas no están en el mercado debido a que faltan pruebas y la aprobación para producirse comercialmente.

Yuca (Manihot esculenta): El CIAT, adelanta seis proyectos de investigación científica en GM, con intención de convertirla en un cultivo altamente industrializado y productivo. Los seis proyectos son: modificación de las características del almidón, reducción de cianuro, enriquecimiento en pro-vitamina A en la raíz, control de floración, aumento en la materia seca y producción de etanol como biocombustible (AGROBIO, 2014)

Pastos (Brachiaria y Styozantes): EI CIAT, trabaja en estas especies de pasto GM. actualmente se realizan estudios de transformación genética para mejoramiento a través de técnicas de ingeniería genética y manejo confinado (AGROBIO, 2014)

Melina (Gmelina arbórea): la melina es una especie de origen asiático, por su amplia adaptabilidad ha sido introducida en países tropicales, posee alto contenido proteico a nivel foliar, se le considera buen forraje para el ganado y sirve de alimento para el gusano de seda. La Universidad Distrital Francisco José de Caldas de Colombia implementó estudios en revigorización y establecimiento in-vitro por medio de cultivos vegetales, el estudio se basó en el rejuvenecimiento fisiológico del material adulto y su establecimiento invitro (Yepes, 2006). 
Nogal (Juglans regia): La Universidad Tecnológica de Pereira en el año 2011 realizó un estudio sobre la caracterización de la variabilidad genética de progenies del nogal, se estudiaron setenta plantas pertenecientes a la estación de mejoramiento en CENICAFE, los resultados de este estudio servirán de guía para la conservación de esta especie (Marulanda, et.al, 2011).

Guadua (Guadua spp.) Uno de los recursos fitogeneticos más representativos del país. En torno esto la Universidad Nacional de Colombia y la Sociedad Colombiana de Bambú realizaron una caracterización molecular de la Guadua angustifolia Kunt por medio de marcadores moleculares RAMs. Se seleccionaron nueve materiales de la zona del eje cafetero por sus características morfológicas y físico-mecánicas. Los resultados obtenidos mostraron que los materiales recolectados de la zona de Pereira no se diferencian genéticamente y pueden ser reproducidos vegetativamente mientras que los de la zona de Palestina (Caldas, Colombia) divergen de las demás zonas; la conclusión final muestra que hay una alta diversidad genética y debido a esta variabilidad se puede pensar en un mejoramiento genético de la especie (Rugeles, Posso, Londoño, Barrera \& Muñoz, 2012).

\section{Sector pecuario}

En el sector pecuario se han realizado grandes avances en la obtención de razas mejoradas, en las cuales se busca un mejor rendimiento de carne, leche y sus derivados; a partir de la clonación de especies con el fin de conservar las características genéticas. Mejorar la alimentación que suministre una adecuada nutrición y resistencia a enfermedades propias de los galpones evitando el uso de la aplicación de hormonas y antibióticos; o con el mejoramiento de las razas avícolas por medio de la transferencia embrionaria que proporcione una resistencia a los cambios climáticos, enfermedades y el tipo de objetivo de producción. En busca del mejoramiento animal se investiga la preservación de los bosques nativos implementando especies arbóreas que sirvan para la alimentación animal. La utilización de la biotecnología ayuda a reducir las importaciones de alimentos y contribuye a disminuir el impacto negativo al medio ambiente con nuevas estrategias de producción pecuaria mediante el diagnóstico, control de enfermedades y la adaptación a los cambios climáticos. En el área animal los avances investigativos se dan con el objetivo de mejorar la producción, creación de vacunas, mejorar las especies ganaderas y clonación manejando la inseminación artificial o implantación de genes.

\section{Algunas investigaciones destacadas en el sector pecuario}

Avicultura: se han desarrollado diferentes estudios para el mejoramiento de la alimentación y así evitar el uso de antibióticos en la cría de estos animales; uno de los estudios realizados fue en la Universidad del Cauca con la incorporación de quinua en la dieta nutricional de pollos de engorde. En el estudio se utilizaron 128 pollos machos Ross 308 a los cuales se les incorporó en la dieta diferentes niveles de quinua. Como resultado se encontraron diferencias en los indicadores de conversión alimentaria, eficiencia alimenticia y rendimiento del canal, en cuanto a la ganancia de peso no se observaron diferencias significativas. En cuanto a los resultados económicos se encontró que "el tratamiento con $5 \%$ de inclusión de quinua representa la mayor rentabilidad siendo un $116 \%$ superior al tratamiento control, obteniendo rendimientos productivos similares a los obtenidos con un concentrado comercial a un más bajo costo" (Mosquera, Portilla \& López, 2009).

Ganadería: uno de los mayores avances se dio a finales del año 2014, cuando nació el primer animal clonado en Colombia en el departamento de Córdoba, este avance se logró por medio de los laboratorios Genescol, se tomó un trozo de piel de la cola de una búfala llamada Lola, este proceso fue realizado un año atrás, se tomó un ovulo al cual le fue extraído el núcleo y se realizó la implantación del núcleo de una célula tomada del trozo de piel. Durante el experimento se realizó el proceso en diferentes búfalas pero solo una culminó con el nacimiento de Lolita. 
Porcicultura: la Universidad Nacional de Colombia logró las primeras crías porcinas con inseminación artificial a partir de semen congelado de diez reproductores donde se logró inseminar a cuatro cerdas. A los 33 días se les hizo ecografía y todas estaban gestando. Después de 312 días, nacieron cuatro camadas, dos de once y dos de siete cerdos, tras una gestación que transcurrió normalmente (Echavarría, 2015).

La aplicación de la biotecnología animal hacia el campo ambiental abre la posibilidad de crear animales que produzcan menor cantidad de daños al ambiente. "El ejemplo más conocido de ese caso es el enviropigTM, un porcino que tiene la capacidad de digerir el fitato de las plantas y de esa forma, liberar menos fosfato en las heces y consecuentemente menos polución ambiental" (Kues \& Niemann, 2004).

Piscicultura. La Universidad del Cauca en la Facultad de Ciencias Agropecuarias en el año 2011 realizó una evaluación de ensilaje biológico de residuos de pescado en alimentación de tilapia roja, el lugar del estudio fue en la represa La Salvajina donde ha incrementado los residuos de la producción piscícola, posteriormente se distribuyeron las diferentes dietas en cuatro grupos al 10, 20, $30 \%$ de ensilaje, y un testigo; como parámetros de evaluación tomaron la digestibilidad aparente y parámetros zootécnicos. Los resultados mostraron que en los parámetros zootécnicos hay diferencias significativas en talla, peso y conversión alimenticia en los tratamientos a los cuales se les añadió el ensilaje siendo "la dieta con inclusión del $30 \%$ de ensilaje biológico de residuos de pescado presentó ganancia de peso, incremento en talla y conversión alimenticia significativamente mayor con respecto a los tratamientos evaluados, relacionado probablemente a los altos niveles de ácidos grasos poliinsaturados" (Perea, Garcés \& Hoyos, 2011). Por su parte, la Universidad del Valle realizó un estudio de bacterias que conservarían la carne de pescado para evitar la pérdida que genera la pesca excesiva y posteriormente contamina los mares ya que los desechos son arrojados nuevamente al mar, las bacterias escogidas para el proyecto son bacterias lácticas, éstas permiten preservar el pescado para la preparación de pasta e hidrolizado de pescado; las bacterias fueron seleccionadas en peces (cardumas, aguja, tamboreros) de la costa pacífica colombiana, se extrajeron sus intestinos donde se encuentran las bacterias para aislar 30 cepas y escoger 3 con mayor capacidad de producción de bacteriocinas; las cepas se siembran en un cultivo puro para elaborar un inoculo direccionado a fermentación bacteriana en dos o tres semanas y finalmente obtener el hidrolizado y pasta de pescado. Este proceso también ha sido empleado para la conservación de verduras, dando como resultado un producto similar al Kimchi coreano; que consiste en verduras fermentadas que se conservan frescas pues no han sido cocinadas y no se les han adicionado preservativos como en el caso de los encurtidos" (Pedraza, 2001).

\section{Desafíos biotecnológicos para fortalecimiento sustentable del agro colombiano}

En la Figura 3 se plantean cinco aplicaciones de la apuesta estrategica del gobierno colombiano en materia de desarrollo biotecnológico, sustentandose en el aprovechamiento de la biodiversidad, y el uso de la bioprospección en la exploración e identificación sistemática de los recursos biológicos con potencial uso en actividades comerciales (Gómez et al., 2013), este panorama permite visualizar de forma positiva el futuro de aplicación sustentable de la biotecnología agropecuaria, enmarcada dentro de las tendencias mundiales citadas a continuación:

- Alimentos saludables, naturales, con buena apariencia y alta calidad nutricional

- Productos $100 \%$ naturales. Reducción del uso de aditivos e ingredientes químicos

- Productos frescos y de larga duración o mínimamente procesados.

- Agricultura libre de agroquímicos - Ecológica

- Alimentos funcionales, fortificados, enriquecidos, con altos contenidos de fibra, dietéticos, y energéticos.

\section{4}


- Interés por productos sofisticados, y buena disposición frente a la variedad y lo exótico con responsabilidad hacia el medio ambiente y la ecología.

- Utilización de la biotecnología para mejorar características nutricionales.
De acuerdo a lo aquí citado la biotecnología actualmente debe propender a la sustentabilidad a partir de prácticas de conservación de los recursos y en pro del bienestar de todos los seres vivos (Narváez, 2015).

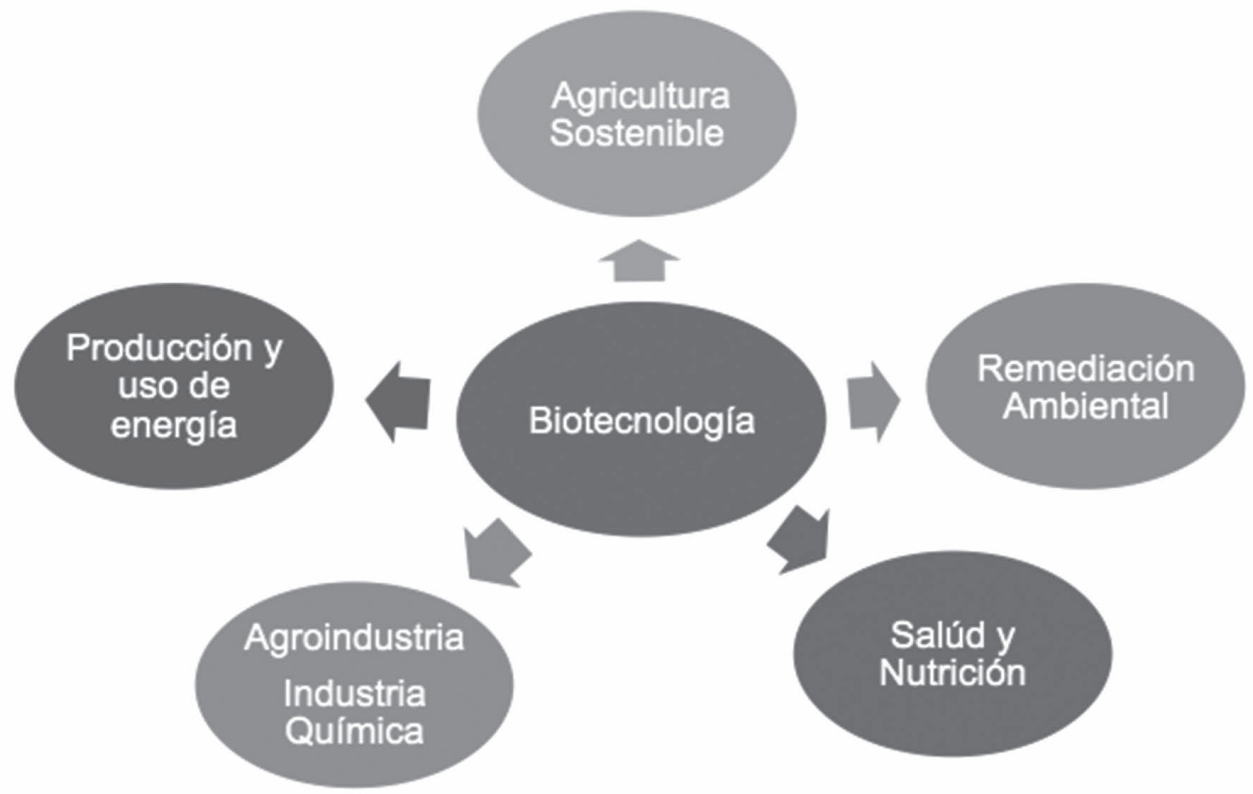

Figura 3. Apuesta estratégica para el sector biotecnológico del gobierno colombiano

Fuente: (Gómez et al., 2013), adaptado del Departamento Nacional de Planeación - PND 2010-2014.

De acuerdo a la publicación de Nieto \& Giraldo (2015) las líneas de acción propuestas por el Programa Nacional de Biotecnología de la política nacional de ciencia, tecnología e innovación de Colombia, no están conectadas correctamente a las tendencias mundiales, lo que significa que es necesario reorientar directrices de las políticas nacionales para que confluyan en una sola dirección encaminada a una producción agropecuaria sustentable. Es un reto para Colombia promover el fortalecimiento del agro colombiano, fundamentalmente para el propio bienestar de sus habitantes y de acuerdo a las tendencias mundiales garantizar la seguridad alimentaria usando como herramienta la investigación en biotecnología, incluyendo sistemas de producción animal en pro del abastecimiento de la demanda proteica; bioprocesos y bioproductos (con macro y microorganismos) relacionados con la creciente demanda de productos con prácticas agrícolas biológicamente racionales; la agrobiodiversidad, en relación con su conservación, uso sostenible y las políticas de acceso y distribución equitativa de beneficios (OECD, 2011). Aplicando de forma responsable las herramientas de desarrollo biotecnológico, Colombia podría salir del mapa del hambre que de acuerdo a la FAO para 2014-16, ubica al país con una población subalimentada del $8.8 \%$ estimada en la categoría de moderadamente baja (FAO, 2015); esto corresponde a 4.4 millones de personas, lo cual no es substancial en términos de disminución a lo largo de los años, si se compara con el periodo 1990-1992 donde esta población sumaba 5 millones (Montenegro \& Rosales, 2015). 


\section{Conclusión}

Considerando que la biotecnología aplicada al sector agroindustrial es la que presenta un mayor desarrollo en Colombia en comparación a otros subsectores, podría visualizarse de forma positiva el futuro de la aplicación sustentable de la biotecnología agropecuaria enmarcada dentro de las tendencias mundiales, no obstante se requiere de esfuerzos significativos en investigación básica y aplicada que coloquen a Colombia a la vanguardia del desarrollo biotecnológico agropecuario.

\section{Literatura citada}

1. AGROBIO. (2006). Investigación en caña GM para protegerla contra virus y enfermedades. CENICAÑA. Recuperado de: http://www.agrobio.org/bfiles/fckimg/ Agro-Bio_Especial_investigacion_cana_GM_Cenicana_Jershon\%20L\%C3\%B3pez.pdf

2. AGROBIO. (2011). Ahora la polilla guatemalteca tendrá miedo de atacar a la papa. Recuperado de: http://agrobio.org/bfiles/fckimg/Especial\%20PAPA\%20GM.pdf

3. AGROBIO. (2014). Transgénicos en el mundo / Región Andina / Colombia. Recuperado de: http://agrobio.org/ fend/index.php?op=YXA912JXbDQmaW09I016UT0=

4. Angarita Bautista, L.J. (sf). Características de la biotecnología. Recuperado de: https://es.scribd.com/ doc/3288567/CARACTERISTICAS-DE-LA-BIOTECNOLOGIA

5. Buitrago Hurtado, G. (2012). Tres décadas de biotecnología en Colombia. Coomb. Biotecnol. Vol 14. n 2. p. 5-6. Recuperado de: http://www.scielo.org.co/pdf/ biote/v14n2/v14n2a01.pdf

6. Cotes Prado, A. M., Barrero Meneses, L. S., Rodríguez Villamizar, F., Zuluaga Mogollón, M. V. \& Arévalo Martínez, H. (2012). Bioprospección para el desarrollo del sector agropecuario de Colombia. Bogotá CORPOICA. $195 \mathrm{p}$.

7. Chaparro Giraldo, A., Cardona, C. A., Orrego, C. E., Alzate, F. C., Yepes Rodrigues, L., Serna Cock, L. \& Ospina Sánchez, S. (2012). Agendas de conocimiento agenda: biotecnología. Universidad Nacional de Colombia. Bogotá. 1a Edición.

8. DaSilva, E.J.(2004).The Colours ofBiotechnology:Science, Development and Humankind. Electronic Journal of Biotechnology, 7(3), 01-02. Recuperado de: http://www. scielo.cl/scielo.php?script=sci_arttext\&pid=S071734582004000300001\&lng=es\&tlng=e.

9. Departamento Nacional de Planeación 2010-2014 "prosperidad para todos". Recuperado de: https://www. dnp.gov.co/Paginas/inicio.aspx
10. Echavarría, A. (2015). Primeras crías porcinas de semen congelado. Universidad Nacional de Colombia. Recuperado de: http://historico.unperiodico.unal.edu. co/ediciones/112/11.html

11. FAO (2004). The state of food and agriculture. Series No. 35. 207 p. [online]. Recuperado de: http://www.fao. org/docrep/006/y5160e/y5160e07.htm

12. FAO (2015). El estado de la inseguridad alimentaria en el mundo- mundial del hambre. [online]. Recuperado de: http://www.fao.org/hunger/es/

13. Fory, L., Tabares, E., Lozano, I., Mora, A., Delgado, G., Agrono, T., Ordoñez, C., Duque, M.C., Calvert, L. \& Lentini, Z. (2002). Arroz transgénico con resistencia al Virus de la Hoja Blanca del Arroz (RHBV) en campo. Centro Internacional de Agricultura Tropical. Recuperado de: http://ciat-library.ciat.cgiar.org/Articulos_CIAT/ poster_transgenico.pdf

14. Gomez, C., H., Benavides, C., P., Osorio Morales, D. \& Cuervo, M., A. (2013) Plan de Acción estrategico Sector Bio de Manizales. Fundación Universidad Empresa Estado del Eje Cafetero. Recuperado de: http://alcaldiamanizales.gov.co/dmd/tic/Plan\%20de\%20Accion\%20Estrategico\%20del\%20Sector\%20Bio\%20Manizales.pdf

15. Gonzales, C. A., Villa Latorre, J. M. \& Bravo, J. E. (2010). La biotecnología como visión de empresa. Biotecnología en el Sector Agropecuario y Agroindustrial, 8(1), 83-92. Recuperado de: http://www.scielo.org.co/scielo.php?script=sci_arttext\&pid=S169235612010000100011\&lng=en\&tlng=es

16. Kues, W. A. \& Niemann, H. (2004). The contribution of farm animals to human health. Trends in Biotechnology, v. 22, p. 286-297. Recuperado de: http://www.ufrgs.br/ depbiot/discipl/BIO12012/farm\%20animals.pdf

17. Marulanda, M., López, A., Uribe, M. \& Ospina, C. (2011). Caracterización de la variabilidad genética de progenies de Cordia alliodora (R. y P.) Oken. Revista Colombia forestal. Vol. 14(2). Recuperado de: http:// www.scielo.org.co/scielo.php?script=sci_arttext\&pid $=$ S0120-07392011000200001

18. Montenegro Gómez, S. P. \& Rosales-Escarria, M. (2015) Fruto de naidi (Euterpe oleracea) y su perspectiva en la seguridad alimentaria colombiana. Entramado. Junio - Diciembre, vol. 11, no. 2, p. 200-207, http://dx.doi. org/10.18041/ entramado.2015v11n2.22238.

19. MoRST. (2005). FutureWatch: Biotecnologies to 2025. New Zeland: Ministry of Research, Science \& Technology of New Zeland.

20. Mosquera, M., Portilla, S. \& López, F. (2009). Evaluación del efecto nutricional de quinua (chenopodium quinoa willdenow) con diferentes niveles de inclusión en dietas para pollos de engorde. Revista Biotecnológica Agropecuaria. Vol. 7 (1). Recuperado de: http://www.scielo.org.co/scielo.php?pid=S169235612009000100010\&script=sci_arttext

21. Narváez, A., (2015). El mercado de la biotecnología en Colombia. Embajada de España en Bogotá. 94 p.

22. Narváez Cuenca, C. E.; Restrepo, L. P.; Benavidez, D.; Bonierbale, M.; Del Castillo, S. E.; DeKöeyer, D.; Thai, 
H.; Kushalappa, A. Kubow, S.; Oxhorn, P.; Perilla, L.; Cuellár, D.; Rodríguez, L. E.; Tinjaca, S. \& Mosquera, T. (2014). nuevos cultivares de papa amarilla con altos rendimientos y contenido nutricional para mejorar el bienestar de comunidades nativas de nariño-colombia en: Eje la Universidad y el desarrollo rural- Foro extención UN, Desarrollo rural en Colombia 85 p. Recuperado de: http://argus.iica.ac.cr/Esp/regiones/andina/colombia/Documentos\%20de\%20la\%20Oficina/Foro_Relaser/Documentos_interes/Memorias-Foro\%20UN_Parte_2.pdf

23. Nieto Gómez, L. E. \& Giraldo Díaz, R. (2015). Tendencies of biotechnology, innovation and development in Colombia. Revista Luna Azul, 41, 348-364. Recuperado de: http://lunazul.ucaldas.edu.co/index. php?option=content\&tas $\mathrm{k}=\mathrm{view} \& \mathrm{id}=1070$

24. Organization for Economic Co-operation and Development (OECD) (2011) "Challenges for Agricultural Research." [on line]. DOI: http://dx.doi. org/10.1787/9789264090101-en. 301p.

25. Organisation for Economic C-operation and Development (OECD) (2009) "The bioeconomy to 2030 Designing a Policy agenda." Challenges for Agricultural Research. [on line]. Recuperado de: www.sourceoecd.org/ generaleconomics/9789264038530

26. Pedraza, C. (2001). Bacteria para conservar la carne de pescado. Agencia universitaria de periodismo científico. Recuperado de: http://aupec.univalle.edu.co/informes/ abril01/peces.html

27. Perea, C., Garcés, Y. \& Hoyos, J. (2011). Evaluación de ensilaje biológico de residuos de pescado en alimentación de Tilapia roja (Oreochromis spp). Revista biotecnología agropecuaria. Vol. 9 (1). Recuperado de: http://www.scielo.org.co/scielo.php?script=sci_arttext\& pid=S1692-35612011000100008

28. Rugeles, P., Posso, A., Londoño, X., Barrera, N. \& Muñoz, J. (2012). Caracterización molecular de Guadua angustifolia Kunth mediante marcadores moleculares RAMs. Revista colombiana de biotecnología. Acta agronómica. Recuperado de: http://www.revistas.unal.edu.co/index.php/acta_agronomica/article/ view/38132/40301

29. Shmaefsky, Brian R. (2013). Agricultural Biotechnology: History, Science, and Society. Bibliographic Essay. CHOISE. p. 199-208.

30. Yepes, A. (2006). Revigorización y establecimiento in vitro de Gmelina arbórea Roxb. V. mediante cultivo de tejidos vegetales. Revista de la universidad distrital Colombia forestal. Vol. 9 (19). Recuperado de: http:// revistas.udistrital.edu.co/ojs/index.php/colfor/article/ view/3351/4861

\section{Conflicto de Intereses}

Los autores declaran no tener ningún conflicto de intereses 
UNAP 